\title{
Multidisciplinary patient care in interventional cardiology
}

\section{Ana Gluhak*, Renata Čosić, Mihaela Fekonja, Ivana Benković, Sandra Benković, Valentina Šimunović, Olvica Benko, Jadranka Daskijević}

University Hospital Centre "Sestre milosrdnice", Zagreb, Croatia
RECEIVED:

February 4, 2018

ACCEPTED:

February 10, 2018

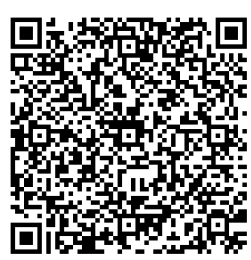

KEYWORDS: implantable cardioverter defibrillator, ventricular tachycardia, ICD storm, electrophysiology CITATION: Cardiol Croat. 2018;13(1-2):27. | https://doi.org/10.15836/ccar2018.27

*ADDRESS FOR CORRESPONDENCE: Ana Gluhak, Klinički bolnički centar Sestre milosrdnice, Vinogradska cesta 29, HR-10000 Zagreb, Croatia. / Phone: +385-95-561-5337 / E-mail: aanna660@gmail.com

ORCID: Ana Gluhak, https://orcid.org/0000-0002-7352-5014 • Renata Čosić, https://orcid.org/0000-0001-6508-7432 Mihaela Fekonja, https://orcid.org/0000-0003-4983-0673 • Ivana Benković, https://orcid.org/0000-0002-1831-0205 Sandra Benković, https://orcid.org/0000-0003-2457-3279 • Valentina Šimunović, https://orcid.org/0000-0002-4702-3651 Ivica Benko, https://orcid.org/0000-0002-1878-0880 • Jadranka Daskijević, https://orcid.org/0000-0001-6547-1098

IIIIIIIIIIIIIIIIIIIIIIIIIIIIIIIIIIIIIIIIIIIIIIIIIIIIIIIIIIIIIIIIIIIIIIIIIIIIIIIIIIIIIIIIIIIIIIIIIIIIIIIIIIIIIIIIIIIII

In this case report we present a case of 73-year-old male (year of birth 1945), urgently admitted to the Cardiac intensive care unit (CICU) of University Hospital Centre "Sestre milosrdnice" on $11^{\text {th }}$ January 2018 due to the multiple implantable cardioverter defibrillator (ICD) activations/shocks at home (for most of which he did not lose consciousness at that time). On the day of admission to the CICU, ten additional shocks were delivered by ICD (also, with no loss of consciousness). The attending physician applied a dose of intravenous magnesium sulphate. Regardless of its application, the ICD storm continued, and 10 more shocks were delivered. Magnet application on the skin and reprogramming of ICD parameters to a more aggressive anti-tachycardia pacing (ATP) and ramp mode was performed by physician. Despite this, in the further course of the hospitalization, there were episodes of both ventricular tachycardia (VT) and ventricular fibrillation (VF) that led to the activation of the ICD (shocks were delivered), but thanks to reprogramming to the more aggressive ATP mode, additional shocks were delivered while the patient was unconscious, causing him to regain sinus rhythm and recover consciousness. On the $5^{\text {th }}$ day, coronary angiography was performed with a placement of one stent in the stronger septal branch of left anterior descending artery. On the $7^{\text {th }}$ day, an electrophysiology study with Carto 3 system was performed during which clinical VT was induced and mapped in the anterolateral part of the left ventricle. The radiofrequency ablation was performed, thus resolving arrhythmia permanently. On the $9^{\text {th }}$ day the patient was transferred to the Post Coronary Care Unit and Arrhythmia Department. During the rest of the patient's stay he reported no pain or discomfort and no malignant ventricular arrhythmias were recorded via telemetry system or ICD memory. On the $13^{\text {th }}$ day, after the treatment was successfully completed, the patient was discharged for further rehabilitation

Goal of this case report was to present the complexity of the treatment of a patient with ICD storm and the importance of multidisciplinary care in interventional cardiology for favorable treatment outcome. ${ }^{1}$ All together represents an extremely demanding need for highly educated nursing staff for various aspects of invasive and interventional cardiology.

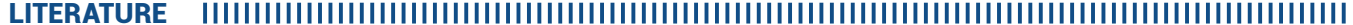

1. Luckraz H, Norell M, Buch M, James R, Cooper G. Structure and functioning of a multidisciplinary 'Heart Team' for patients with coronary artery disease: rationale and recommendations from a joint BCS/BCIS/SCTS working group. Eur J Cardiothorac Surg. 2015 0ct;48(4):524-9. https://doi.org/10.1093/ejcts/ezv083 